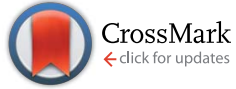

Cite this: RSC Adv., 2015, 5, 52243

Received 14th May 2015 Accepted 5th June 2015

DOI: $10.1039 / c 5 r a 09039 c$

www.rsc.org/advances

\section{Deciphering the electron transfer mechanisms for biogas upgrading to biomethane within a mixed culture biocathode $\uparrow$}

\author{
Pau Batlle-Vilanova, ${ }^{a}$ Sebastià Puig, ${ }^{\text {*a }}$ Rafael Gonzalez-Olmos, ${ }^{\text {ab }}$ Anna Vilajeliu-Pons, ${ }^{a}$ \\ M. Dolors Balaguer ${ }^{a}$ and Jesús Colprim ${ }^{a}$
}

Biogas upgrading is an expanding field dealing with the increase in methane content of the biogas to produce biomethane. Biomethane has a high calorific content and can be used as a vehicle fuel or directly injected into the gas grid. Bioelectrochemical systems (BES) could become an alternative for biogas upgrading, by which the yield of the process in terms of carbon utilisation could be increased. The simulated effluent from a water scrubbing-like unit was used to feed a BES. The BES was operated with the biocathode poised at $-800 \mathrm{mV}$ vs. SHE to drive the reduction of the $\mathrm{CO}_{2}$ fraction of the biogas into methane. The BES was operated in batch mode to characterise methane production and under continuous flow to demonstrate its long-term viability. The maximum methane production rate obtained during batch tests was $5.12 \pm 0.16 \mathrm{mmol} \mathrm{m}^{-2}$ per day with a coulombic efficiency (CE) of $75.3 \pm 5.2 \%$. The production rate increased to $15.35 \mathrm{mmol} \mathrm{m}{ }^{-2}$ per day (CE of $68.9 \pm 0.8 \%$ ) during the continuous operation. Microbial community analyses and cyclic voltammograms showed that the main mechanism for methane production in the biocathode was hydrogenotrophic methanogenesis by Methanobacterium sp., and that electromethanogenesis occurred to a minor extent. The presence of other microorganisms in the biocathode, such as Methylocystis sp. revealed the presence of side reactions, such as oxygen diffusion from the anode compartment, which decreased the efficiency of the BES. The results of the present work offer the first experimental report on the application of BES in the field of biogas upgrading processes.

\section{Introduction}

Anaerobic digestion (AD) is a widespread process to produce biogas through the valorisation of solid and liquid organic wastes. Biogas consists of a mixture of mainly methane $\left(\mathrm{CH}_{4}\right.$; $35-65 \%)$ and carbon dioxide $\left(\mathrm{CO}_{2} ; 15-50 \%\right)$ with trace amounts of other compounds (i.e. hydrogen sulphide $\left(\mathrm{H}_{2} \mathrm{~S}\right)$, volatile organic compounds, siloxanes and water), which can be used in cogeneration units to obtain energy in the form of heat and electricity. ${ }^{1}$

The term biomethane has been used to describe methanerich biogas $(95 \% \mathrm{v} / \mathrm{v})$ from $\mathrm{AD}$ of organic wastes, which could be directly used as a vehicle fuel or injected into the gas grid. ${ }^{2}$ Biogas upgrading technologies imply (i) the removal of harmful trace components, and (ii) the upturn of the methane content to

${ }^{a}$ LEQUiA, Institute of the Environment, University of Girona, Campus Montilivi, E-17071 Girona, Catalonia, Spain. E-mail: sebastia@lequia.udg.cat; Fax: +34 972418150; Tel: +34 972418281

${ }^{b}$ Chemical Engineering Department, IQS-School of Engineering, Ramon Llull University, Via Augusta 390, Barcelona 08017, Spain

† Electronic supplementary information (ESI) available. See DOI: $10.1039 / \mathrm{c} 5 \mathrm{ra09039c}$ increase the calorific capacity of the biogas. ${ }^{3}$ According to the International Energy Agency (IEA), water scrubbing is the most used technique for biogas upgrading, accounting for about $40 \%$ of the total upgrading plants. ${ }^{4}$ This technology consists of an absorption tower where $\mathrm{CO}_{2}$ is absorbed in water and biomethane is obtained. The absorbed $\mathrm{CO}_{2}$ is released to the atmosphere in a subsequent stripping tower, ${ }^{5}$ what often implies the consumption of energy. The transformation of the $\mathrm{CO}_{2}$ contained in the effluent of the absorption tower into methane could be a useful strategy to increase the biomethane production and could contribute to reduce the $\mathrm{CO}_{2}$ emissions. In this light, bioelectrochemical systems (BES) can be a promising technology to drive the reduction of dissolved $\mathrm{CO}_{2}$ into methane. Some authors already proposed the coupling of BES with $\mathrm{AD}$ in single reactors to increase the yield of the whole process. ${ }^{6-8}$ This work proposes a new promising application for BES, which is the replacement of the stripping tower of a water scrubbing unit for biogas upgrading. The possibility of coupling water scrubbing and BES opens the door to an innovative hybrid process. The bioelectrochemical conversion of $\mathrm{CO}_{2}$ to methane is known as electromethanogenesis, and was first presented by Cheng and coworkers. ${ }^{9}$ Other researchers studied the methane production mechanism at different cathode potentials, and the 
performance at the long term operation..$^{\mathbf{1 0} 11}$ Accordingly, methane production can take place in a biocathode mainly by two mechanisms: (i) hydrogenotrophic methanogenesis (eqn (1)), using hydrogen as electrochemical mediator, which can be produced in situ either bioelectrochemically or electrochemically, ${ }^{12}$ and (ii) using directly electrons as reducing power source (eqn (2)).

$$
\begin{gathered}
\mathrm{CO}_{2}+4 \mathrm{H}_{2} \rightarrow \mathrm{CH}_{4}+2 \mathrm{H}_{2} \mathrm{O} \\
\mathrm{CO}_{2}+8 \mathrm{H}^{+}+8 \mathrm{e}^{-} \rightarrow \mathrm{CH}_{4}+2 \mathrm{H}_{2} \mathrm{O} ; E_{0}^{\prime}=-240 \mathrm{mV} \text { vs. } \mathrm{SHE}^{13}
\end{gathered}
$$

Methane production using hydrogen as intermediate was shown to be the predominant mechanism in methane producing biocathodes poised at low cathode potentials (i.e. $<-750 \mathrm{mV}$ vs. SHE). ${ }^{11}$ Nevertheless, Eerten-Jansen et al., also suggested the production of methane through other intermediates, such as acetate or formate. ${ }^{14}$ The conversion of $\mathrm{CO}_{2}$ to methane through direct electron transfer was suggested by Cheng et al., 2009 and Fu et al., 2015, who used a pure culture of Methanobacterium palustre and thermophilic methanogens, respectively.9,15 Finally, both direct and hydrogen mediated electron transfer took place in the biocathodes studied by Siegert and co-workers. ${ }^{16}$ Syntrophic relationships, such as interspecies hydrogen transfer and direct interspecies electron transfer (DIET) have been also proposed for the production of methane with mixed cultures, being the last one more energetically conservative due to the fact that electrons are directly transferred between microorganisms, avoiding the production of intermediates. ${ }^{17,18}$ So far, there is only one study that demonstrated the DIET between two pure cultures. ${ }^{19}$ Since mixed cultures have been usually utilised for the production of methane, the mechanism by which it is produced in a biocathode may differ among different studies. Thus, methane production mechanism in biocathodes is still unclear, so that more studies regarding the microorganisms involved and its electrochemical interaction with the electrode surface are needed to understand and optimise the whole process.

The present work proposes the coupling of water scrubbing with BES for biogas upgrading. The methane production and the electrochemical performance of the BES were studied. Electrochemical and microbiological analyses were carried out to understand how the microbial community dealt with the reducing power, ${ }^{13}$ which microorganisms were involved in the electron transfer, and which intermediates and final products affected the bioelectrochemical performance of the BES.

\section{Experimental}

\section{BES construction}

A two-chambered BES was constructed using a previous described design by Batlle-Vilanova et al. ${ }^{20}$ A schematic representation of the BES design and the equipment is presented in the ESI (Fig. S1 $\dagger$ ). In the present study, after the graphite replenishment of the compartments, the net anode compartment (NAC) and the net cathode compartment (NCC) volumes were $410 \mathrm{~mL}$ and $420 \mathrm{~mL}$, respectively. The resulting cathode electrode surface was $0.57 \mathrm{~m}^{2}$ (see ESI, Section $\mathrm{S} 2 \dagger$ ). The system was thermostatically controlled at $34.7 \pm 1.1{ }^{\circ} \mathrm{C}$ and under atmospheric pressure conditions.

The BES was operated in a three-electrode configuration with a potentiostat (BioLogic, model VSP, France), which controlled the cathode potential and monitored the current demand. The biocathode was used as working electrode (WE) and the anode as counter electrode, the reference electrode (RE) was an $\mathrm{Ag}$ / AgCl (+197 mV vs. Standard Hydrogen Electrode [SHE], model RE-5B, BASI, United Kingdom) placed in the cathode chamber. All voltages within this study are reported with respect to SHE.

\section{BES start-up}

The operational period of the BES was divided into different stages depending on the mode of operation (Fig. S2 $\dagger$ ). The cathode was inoculated in closed circuit voltage (CCV) mode at $-600 \mathrm{mV}$. As inoculum, $100 \mathrm{~mL}$ of diluted effluent from an anaerobic digester were used. The inoculum was continuously recirculated at a high flow of $150 \mathrm{~L}$ per day for 6 days to generate stress conditions to the microorganisms and to force them to get attached to the electrode surface. The anode was not inoculated and water was used as electron donor $\left(\mathrm{H}_{2} \mathrm{O} / \mathrm{O}_{2} E^{\prime}{ }_{0}=820 \mathrm{mV}\right)$. Synthetic medium was used in both anode and cathode compartments, which was prepared based on ATCC1754 growth medium, ${ }^{21}$ and was already described elsewhere. ${ }^{20} \mathrm{CO}_{2}(99.9 \%$, Praxair, Spain) was directly bubbled into the mineral solution to ensure saturated conditions $\left(24.9 \mathrm{mM}\right.$ at $\left.34.7^{\circ} \mathrm{C}\right)$. The start-up period commenced after the inoculation. The biocathode was poised at $-600 \mathrm{mV}$, and continuously fed with $553 \pm 16 \mathrm{~mL}$ per day of synthetic medium, which resulted in a cathode hydraulic retention time (HRT) of $18.3 \pm 0.5 \mathrm{~h}$. At day 64 of the start-up period, the $\mathrm{HCO}_{3}{ }^{-}$was removed from the influent. At day 75, the cathode potential was decreased to $-800 \mathrm{mV}$ to increase the amount of reducing power supplied to the biocathode. After 159 days, batch tests were performed with synthetic biogas $\left(55 \% \mathrm{CH}_{4}\right.$, $45 \% \mathrm{CO}_{2}$, Praxair, Spain) instead of $\mathrm{CO}_{2}$, which was bubbled into the mineral solution and used as carbon source to simulate the effluent of an absorption tower from a biogas scrubbing process.

\section{Batch operation}

Thirteen batch tests were consecutively performed in the biocathode under the same conditions, unless otherwise stated. Test 6 was performed in open circuit voltage (OCV), without applying any voltage, to check whether the biocathode was able to produce methane by non-electrochemical mechanisms. Batch tests lasted between 4 and 10 days. Before each batch test, the biocathode and the anode were washed with synthetic medium with 3 times the net volume of each chamber. The biocathode was connected to a methacrylate chamber filled with the same medium to collect the gas produced.

Gas samples were taken regularly to quantify the methane production, and liquid samples to check the concomitant production of other valuable compounds in the liquid phase (i.e. volatile fatty acids [VFA] and alcohols). A pH sensor (model 5303, Crison, Spain) was placed in the cathode recirculation 
loop to measure the $\mathrm{pH}$ with a transmitter (MultiMeter MM44, Crison, Spain) connected to a memograph (Graphic data manager RSG40, Memograph M, Endress+Hauser, Switzerland).

After the batch tests the BES was operated in continuous mode, under the same conditions than during the start-up period (Fig. S2 $\dagger$ ), to validate the operational stability of the BES in the long-term.

\section{Analyses and calculations}

Liquid and gas analyses. The composition of the gas phase was analysed with an Agilent 7890A (Agilent Technologies, US) gas chromatograph (GC) equipped with an HP-Molesieve column and a thermal conductivity detector (TCD) to detect hydrogen, oxygen, nitrogen, methane, carbon monoxide and $\mathrm{CO}_{2} \cdot{ }^{20} \mathrm{VFA}$ and alcohols in the liquid phase were analysed in a second channel of the same GC equipped with a DB-FFAP column and a flame ionisation detector (FID). ${ }^{20}$ Sulphate concentration $\left(\mathrm{SO}_{4}{ }^{2-}\right.$ ) was analysed according to the standard methods for the examination of water and wastewater. ${ }^{22} \mathrm{~A}$ presence/absence analysis of $\mathrm{H}_{2} \mathrm{~S}$ in the gas phase was conducted with a CP-3800 GC (Varian, US) equipped with a pulsed flame photometric detector (PFPD) and a GS-GasPro column (Agilent Technologies, US).

All of the production rates are given in mmol of carbon per $\mathrm{m}^{2}$ of electrode surface per day ( $\mathrm{mmol} \mathrm{m} \mathrm{m}^{-2}$ per day).

Calculation of coulombic and energy efficiency. The efficiency on electron removal or supply by a BES through an electrical circuit has been traditionally referred to as coulombic efficiency (CE), ${ }^{23}$ and it is calculated as shown in eqn (3): ${ }^{24}$

$$
\mathrm{CE}(\%)=\frac{8 F n_{\mathrm{CH}_{4}}}{\int_{t_{0}}^{t_{\mathrm{i}}} I(t) \mathrm{d} t} \times 100
$$

where, 8 are the number of electrons consumed per mole of methane produced, $F$ is Faraday's constant (96485 $\mathrm{C} \mathrm{mol}^{-1}$ ), $n_{\mathrm{CH}_{4}}$ are the moles of methane produced between $t_{0}$ and $t_{\mathrm{i}}$, and $I(t)$ is the current (A) integrated over time (from $t_{0}$ to $t_{\mathrm{i}}$ in seconds).

The energetic efficiency of the process $\left(\eta_{\mathrm{E}}\right)$ was calculated according to eqn (4): ${ }^{10,24}$

$$
\eta_{\mathrm{E}}(\%)=\frac{-\Delta G_{\mathrm{CH}_{4}} n_{\mathrm{CH}_{4}}}{E_{\text {cell }} \int_{t_{0}}^{t_{1}} I(t) \mathrm{d} t} \times 100
$$

where $\Delta G_{\mathrm{CH}_{4}}$ is the Gibbs free energy of methane oxidation $\left(-890.4 \mathrm{~kJ} \mathrm{~mol}^{-1}\right),{ }^{25}$ and $E_{\text {cell }}$ is the voltage applied to the cell (V).

Cyclic voltammetry analyses. Electrochemical analyses were conducted in a single-chamber BES according to Pous et al., $2015{ }^{26}$ Three different tests were prepared with fresh medium for (i) abiotic conditions, (ii) biocathode microorganisms, and (iii) biocathode microorganisms after medium exchange. All the cyclic voltammograms (CV) were performed under turnover conditions. Before the CV performed with microorganisms from the biocathode, a chronoamperometry at $-800 \mathrm{mV}$, was performed during $120 \mathrm{~h}$ previous to the $\mathrm{CV}$ to favour the microorganisms' growth. The last $\mathrm{CV}$ was performed 30 minutes after the medium exchange. Platinum wire, graphite rod (9.74 $\mathrm{cm}^{2}$ ), and $\mathrm{Ag} / \mathrm{AgCl}$ were used as counter electrode, WE and $\mathrm{RE}$, respectively. The cathode was poised at $-800 \mathrm{mV}$. When current demand was observed, the CVs were performed. The scan window was from 0 to $-800 \mathrm{mV}$, and the scan rate $10 \mathrm{mV} \mathrm{s}^{-1}$. Three cycles were performed in each $\mathrm{CV}$ and data from the last cycle is shown.

Biocathodic community analyses. At day 188, between batch test 2 and 3, the BES was opened and about $26 \mathrm{~g}$ of granular graphite from different parts of the biocathode were extracted and integrated to assess the microbial community composition.

DNA was extracted using the Fast DNA ${ }^{\circ}$ SPIN Kit for soil (MP Biomedicals, US) according to the manufacturer's instructions. DNA quantification was assessed with a nanodrop spectrophotometer (Thermo Scientific, US) characterized by 260/280 and $260 / 230 \mathrm{~nm}$ absorbance ratio in order to be comparable with quantitative real-time PCR (qPCR).

Bacterial diversity and microbial community structure of the cathode biofilm was analysed for 454 pyrosequencing (Research and Testing Laboratory, Lubbock, US). The 16S rRNA gene was analysed by primers $341 \mathrm{~F}-907 \mathrm{R}$ for bacteria, ${ }^{27}$ and $341 \mathrm{~F}-958 \mathrm{R}$ for archaea. ${ }^{28}$ Sequences obtained were analysed using MOTHUR software (v. 1.22.1) at $97 \%$ similarity. ${ }^{29}$ Sequences shorter than $250 \mathrm{bp}$ and longer than $600 \mathrm{bp}$ were excluded. Chimeric sequences were discarded by executing UCHIME. ${ }^{30}$ These sequences were then clustered into OTUs using the UPARSE algorithm. ${ }^{31}$ Taxonomic classification was done by RDP classifier. ${ }^{32}$ The most abundant sequences of bacteria and archaea were compared to BLAST supported by NCBI in order to obtain the closest similarity related to genbank database sequence. Alignments and identity matrix comparisons of deposited sequences were performed in BioEdit (v. 7.0). ${ }^{33}$ Post-data analysis was done by KRONA. ${ }^{34}$

Additionally, 16S rRNA gene was also quantified by qPCR to estimate the total amount of bacteria and archaea. All reactions were performed in a 7500 Real Time PCR system (Applied Biosystems, US) using the SYBRH Green PCR Mastermix. Primers and thermal cycling conditions for bacteria $(341 \mathrm{~F}-534 \mathrm{R})$ and archaea (364af-A934b) 16S rRNA were used..35,36 Results were analysed using SDS software (Applied Biosystems, US). Standard curves were obtained using serial dilutions from $10^{2}$ to $10^{7}$ copies of linearised plasmids containing the respective functional genes. Controls without templates gave null or negligible values.

\section{Results}

\section{Inoculation and start-up periods}

According to the results observed by Marshall et al., the biocathode was poised at $-600 \mathrm{mV}$, because they demonstrated that the concomitant production of acetate, methane and hydrogen occurred at that potential. ${ }^{37} \mathrm{~A}$ negligible current demand was observed in the biocathode along the first part of the start-up period (Fig. S3 $\dagger$ ). At day 64, the $\mathrm{NaHCO}_{3}$ added to the medium was removed, causing a slightly decrease of the medium $\mathrm{pH}$ (from $6.7 \pm 0.5$ to $5.4 \pm 0.2$ ), which favoured inorganic carbon speciation towards $\mathrm{CO}_{2}$. Up to day 75 , neither gas nor organic 
compounds production was observed in the biocathode. The average current demand from day 64 to day 75 was around $1.1 \pm$ $0.2 \mathrm{~mA} \mathrm{~m}^{-2}$. At day 75 the cathode potential was decreased to $-800 \mathrm{mV}$ to increase the amount of reducing power supplied to the biocathode. From that point on, the current demand increased and methane was detected as the main product. At day 159, when the current demand stabilised around $28.6 \pm 0.6 \mathrm{~mA}$ $\mathrm{m}^{-2}$, batch tests were performed in the biocathode to characterise and quantify the methane production.

\section{Performance of the biocathode during operation}

After the start-up period, different consecutive batch tests were performed in the biocathode under the same conditions. The tests were ordered chronologically and identified with a number. The results obtained for the different tests are shown in Table 1. Methane production rate, $\mathrm{CE}$ and $\eta_{\mathrm{E}}$ for each test were obtained from the linear plot between the mmol of methane produced over time. The most representative tests are presented in the ESI (Fig. S4†).

Analyses of the liquid phase revealed that compounds such as VFA and alcohols were not produced in the biocathode. Nevertheless, sulphate concentration in the influent was $3.6 \mathrm{mg}$ $\mathrm{L}^{-1}$, and it was not detected in the effluent, so sulphates were completely consumed in the biocathode. Qualitative analyses demonstrated the presence of $\mathrm{H}_{2} \mathrm{~S}$ in the off gas. Methane was detected in the gas phase with a volumetric concentration of 65$85 \%$, being the rest $\mathrm{CO}_{2}(15-35 \%)$ and trace amount of oxygen (1-8\%) and $\mathrm{H}_{2} \mathrm{~S}$.

The overall performance of the biocathode from tests 1 to 5 was very similar. The $\mathrm{pH}$ in those tests was around 6 . The current demand ranged from $27.3 \pm 2.4$ to $40.8 \pm 3.5 \mathrm{~mA} \mathrm{~m}^{-2}$, and the production rate from 1.36 to $1.89 \mathrm{mmol} \mathrm{m}^{-2}$ per day was obtained with associated CEs from $39.0 \pm 1.6$ to $51.7 \pm$ $4.5 \%$. Test 6 was performed in OCV mode. A 20 -fold lower amount of methane was produced and the $\mathrm{pH}$ decreased 1.4 units compared to the previous test, which was caused by the lack of electrochemical activity in the biocathode. The BES was negatively affected after the OCV test.
Subsequent tests (i.e. 7 to 9) showed a lower performance in terms of current demand and methane production rate. Biogas was directly flushed to the biocathode once per day during test 10 and 11 to favour substrate availability, displace oxygen diffused to the cathode, and promote the growth of methanogenic microorganisms. The current demand was monitored as a parameter indicating the activity of the biocathode. By applying this strategy the system recovered, and after 2 batch tests (i.e. test 12) the performance was similar to the previous tests. Test 12 showed similar performance to tests 1 to 5 (Table 1). In the subsequent and last test, the activity increased, obtaining a higher current demand of $70.7 \pm 6.6$ $\mathrm{mA} \mathrm{m} \mathrm{m}^{-2}$ and a production rate of $5.12 \pm 0.16 \mathrm{mmol} \mathrm{m}^{-2}$ per day, with a CE of $75.3 \pm 5.2 \%$, which coincided with the higher $\mathrm{pH}$ (i.e. 7.1) of the biocathode. Comparative analysis (Fig. S5†) showed that methane production rate was linearly related $\left(r^{2}=\right.$ $0.99)$ to the current demand of the biocathode. The higher the current demand was, the higher the methane production rate. No evidence of dependence between the production rate and other parameters (i.e. $\mathrm{pH}$ and $\mathrm{CE}$ ) was observed in this study (Fig. S5†). Although it was not investigated in the present study, previous studies suggested that other parameters, such as temperature, inoculum source or electrode materials could affect methane production. ${ }^{\mathbf{1 6 , 3 8 , 3 9}}$ The $\eta_{\mathrm{E}}$ during the firsts tests (i.e. test 1 to test 5 ) were similar, ranging from $21.2 \pm 1.8$ to $31.7 \pm 2.1 \%$, and increased to $39.7 \pm 3.6 \%$ in the last batch test (i.e. test 13$)$.

After batch tests, the BES was operated in continuous flow under the same conditions than the start-up period (Fig. S2 $\dagger$ ). Fig. 1 shows the evolution of the current demand and the production rate during this period. The average methane production rate during the first days was $3.99 \pm 0.06 \mathrm{mmol} \mathrm{m}^{-2}$ per day, which increased and stabilised at $15.35 \mathrm{mmol} \mathrm{m}^{-2}$ per day after 43 days of continuous operation. The results regarding the continuous operation are included in Table 1 (test 14) and correspond to the results obtained at the end of the period, when current demand and production rate were stable. The CE and the $\eta_{\mathrm{E}}$ obtained during the continuous operation were $68.9 \pm 0.8 \%$ and $39.7 \pm 1.3 \%$, respectively, which were close to

Table 1 Tests with biogas as the sole carbon source. OCV: open cell voltage; $n / a$ : not available

\begin{tabular}{|c|c|c|c|c|c|c|c|}
\hline Test & Operation mode & $\begin{array}{l}\text { Current demand } \\
\left(\mathrm{mA} \mathrm{m}^{-2}\right)\end{array}$ & $\mathrm{pH}$ & $r^{2}$ & $\begin{array}{l}\text { Production rate } \\
\left(\mathrm{mmol} \mathrm{CH}_{4} \mathrm{~m}^{-2} \text { per day) }\right.\end{array}$ & CE (\%) & $\eta_{\mathrm{E}}(\%)$ \\
\hline 1 & Batch & $32.0 \pm 2.4$ & $6.1 \pm 0.1$ & 0.998 & $1.63 \pm 0.01$ & $45.3 \pm 1.9$ & $26.4 \pm 2.0$ \\
\hline 3 & Batch & $31.1 \pm 6.8$ & $6.3 \pm 0.1$ & 0.996 & $1.36 \pm 0.02$ & $47.9 \pm 5.8$ & $23.7 \pm 5.8$ \\
\hline 4 & Batch & $32.8 \pm 5.2$ & $6.1 \pm 0.2$ & 0.981 & $1.89 \pm 0.05$ & $45.9 \pm 3.6$ & $30.3 \pm 4.5$ \\
\hline 5 & Batch & $27.3 \pm 2.4$ & $6.0 \pm 0.1$ & 0.999 & $1.67 \pm 0.02$ & $51.7 \pm 4.5$ & $31.7 \pm 2.1$ \\
\hline 8 & Batch & $11.0 \pm 1.9$ & $5.5 \pm 0.3$ & 0.992 & $0.30 \pm 0.01$ & $25.1 \pm 4.7$ & $14.5 \pm 2.7$ \\
\hline 9 & Batch & $6.9 \pm 0.7$ & $6.7 \pm 0.1$ & 0.952 & $0.19 \pm 0.01$ & $25.1 \pm 2.3$ & $14.5 \pm 1.3$ \\
\hline 10 & Batch & $7.2 \pm 0.4$ & $6.7 \pm 0.1$ & $\mathrm{n} / \mathrm{a}$ & $\mathrm{n} / \mathrm{a}$ & $\mathrm{n} / \mathrm{a}$ & $\mathrm{n} / \mathrm{a}$ \\
\hline 11 & Batch & $11.9 \pm 3.3$ & $6.6 \pm 0.1$ & $\mathrm{n} / \mathrm{a}$ & $\mathrm{n} / \mathrm{a}$ & $\mathrm{n} / \mathrm{a}$ & $\mathrm{n} / \mathrm{a}$ \\
\hline 12 & Batch & $31.2 \pm 10.2$ & $6.8 \pm 0.1$ & 0.975 & $1.38 \pm 0.05$ & $54.2 \pm 8.3$ & $25.3 \pm 7.8$ \\
\hline 13 & Batch & $70.7 \pm 6.6$ & $7.1 \pm 0.1$ & 0.989 & $5.12 \pm 0.16$ & $75.3 \pm 5.2$ & $39.7 \pm 3.6$ \\
\hline
\end{tabular}




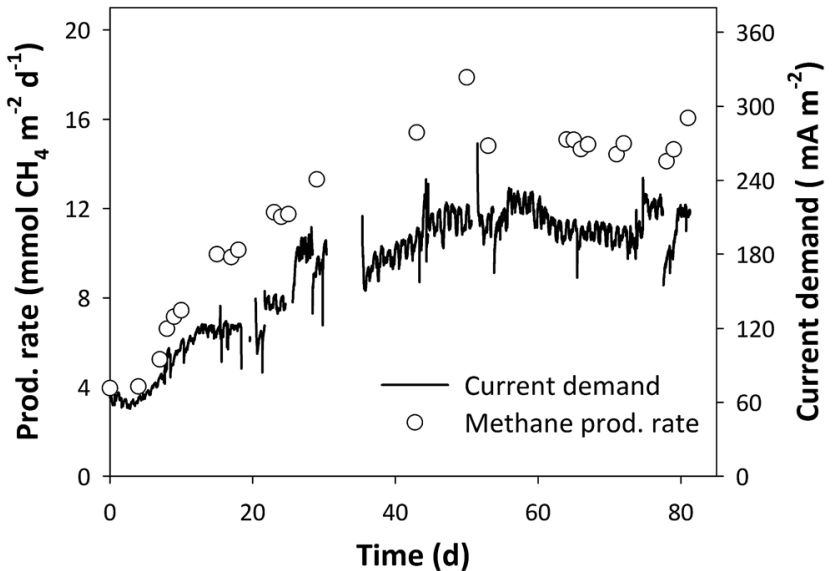

Fig. 1 Current demand and methane production rate of the biocathode during the continuous operation after the batch tests.

the last batch test, whilst the current demand and the methane production rate were triplicated.

\section{Biocathode microbial community}

Preliminary observations using scanning electron microscopy suggested that the biocathode consisted of a dense microbial community (Fig. S6 $\dagger$ ). Results of the specific microbial community analysis through pyrosequencing for archaea and bacteria are shown in Fig. 2. More detailed results of the pyrosequencing analyses are shown in Fig. S7. $\dagger$ Archaea and bacteria community analysis showed abundances of $3.36 \times 10^{6}$ DNA copies per $g_{\text {graphite }}$ and $2.77 \times 10^{6}$ DNA copies per $g_{\text {graphite }}$, respectively, which means that the biocathode was composed by $55 \%$ of archaea and $45 \%$ of bacteria. Methanobacterium sp. dominated the archaea community (Fig. 2A). Methanobacterium subterraneum composed $10 \%$ of the Methanobacterium genus, which was identified with a similarity of $99 \%$ among other nonidentified species.

Bacteria community presented higher diversity of phylums than archaea (Fig. 2B). Proteobacteria composed 51\% of the

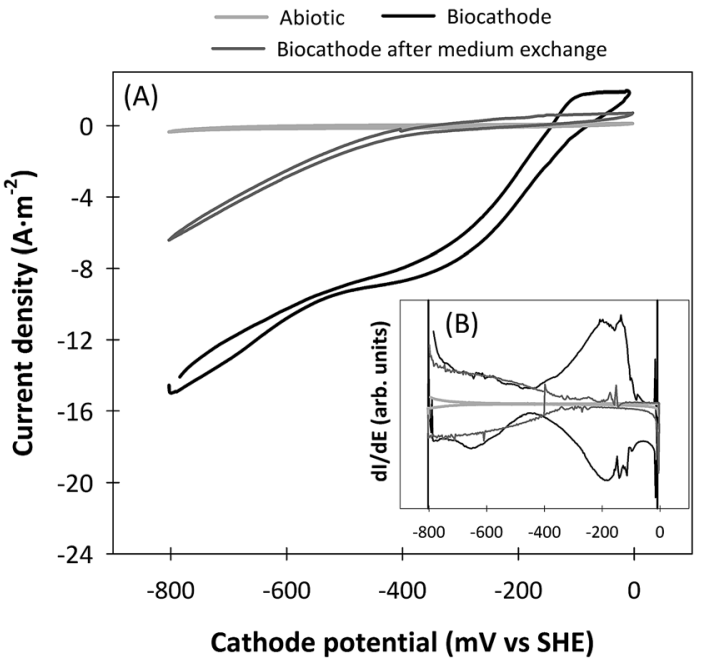

Fig. 3 Cyclic voltammetry tests performed under abiotic (grey) and in turnover conditions before (black) and after (dark grey) medium exchange in the presence of microorganisms from the biocathode $(A)$, and first derivative of the respective CVs (B). Previously to the electrochemical experiments the microorganisms were grown on $\mathrm{CO}_{2}$ at a cathode potential of $-800 \mathrm{mV}$ for 120 hours. The scan rate was of $10 \mathrm{mV} \mathrm{s}^{-1}$

sample, more concretely Alphaproteobacteria (32\%). The dominant genus of the Alphaproteobacteria was identified as Methylocystis sp. (20\%). The rest of the community was divided in several phylums, highlighting the presence of Firmicutes (Clostridium sp. $12.0 \%$ ) and Bacteroidetes (Anaerophaga sp. 5.6\%).

\section{Electrochemical characterisation}

CVs were performed in microcosms using the effluent of the biocathode to figure out which was the predominant methane production mechanism. The results of the CVs and its first derivatives are presented in Fig. 3. Abiotic CVs showed a plain shape, demonstrating that redox active species were not present in the synthetic medium. Current density was low, and
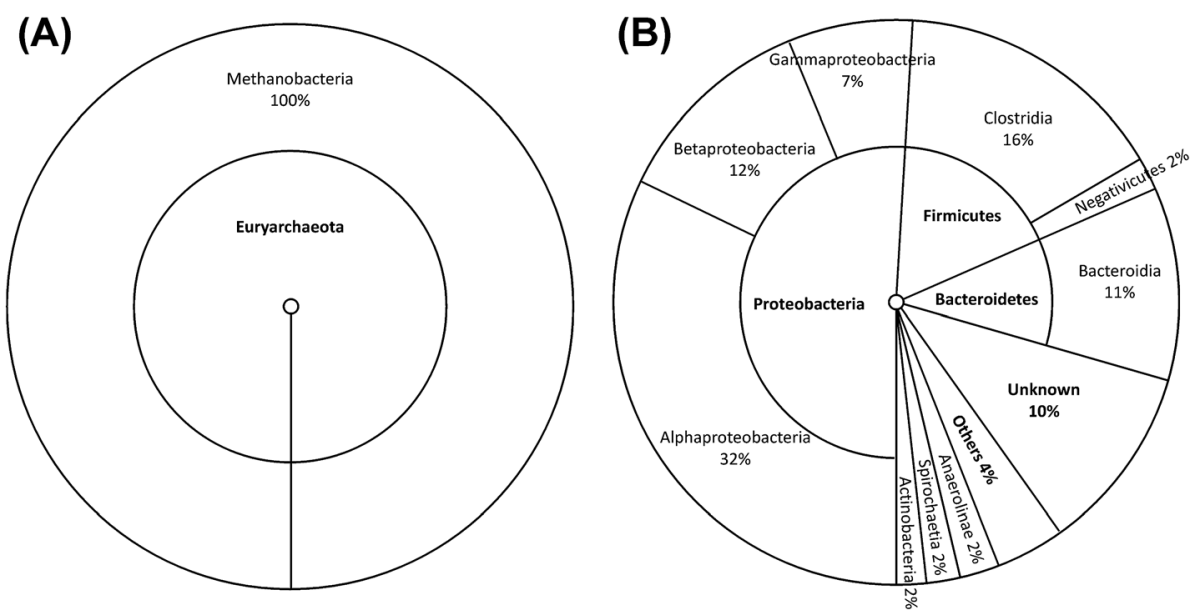

Fig. 2 Results of the microbial community analysis of archaea (A) and bacteria (B) present the biocathode. 
hydrogen reductive wave appeared at very negative potentials, such as $-640 \mathrm{mV}$. After a growth phase of 120 hours, the CVs performed with microorganism from the biocathode showed a higher current density. One cathodic catalytic wave was observed at a midpoint potential of $-190 \mathrm{mV}$. Similarly, another catalytic wave, typically related to hydrogen production, ${ }^{12}$ was also observed, which started at a potential of $-440 \mathrm{mV}$. In the $\mathrm{CV}$ performed after the medium exchange the reductive wave allocated at $-190 \mathrm{mV}$ disappeared, whereas hydrogen reductive wave remained.

\section{Discussion}

\section{Methane production}

The methane production rate was directly related to the current demand of the biocathode. The low quantity of methane detected during the OCV test confirmed that methane production mostly relied on the electricity provided to the biocathode, and previous studies demonstrated that methane was not abiotically produced at such cathode potential.11,12 Thus, methane production in the biocathode was bioelectrochemically driven.

The lower current demand and methane production after the OCV test were likely caused by the lack of available reducing power for a period of about 70 hours. Thus, nonelectrochemical microorganisms present in the biocathode, such as Methylocystis sp. were favoured over methanogens during the OCV test. Another hypothesis was that the lack of activity caused the $\mathrm{pH}$ inside the biocathode being similar to the influent $\mathrm{pH}$, which was close to 5 . At such low $\mathrm{pH}$ values, the methanogenic metabolism could be inhibited, ${ }^{\mathbf{4 0}}$ so that, after the OCV test it took time to recover the previous performance. Otherwise, the increased activity of the last batch test could have been caused by a higher $\mathrm{pH}$ of the biocathode. While previous tests had not significant differences of $\mathrm{pH}$, being its value around 6 , in test 13 it increased to 7.1 , likely due to the higher current demand and the increase of the bioelectrochemical activity. Although substrate availability is lower at high $\mathrm{pH}$ values, ${ }^{20}$ some microorganisms from Methanobacterium sp. have been reported to grow better at $\mathrm{pH}$ higher than 6.5 , with optimum growth values even higher than $7 .^{\mathbf{4 1}}$ Thus, the $\mathrm{pH}$ conditions were more favourable for the methanogens. The effect of the $\mathrm{pH}$ in the electromethanogenic biocathode cannot be contrasted to other studies because it has not been reported yet.

The results regarding the continuous operation (i.e. test 14) were similar to the last batch tests in terms of $\mathrm{pH}, \mathrm{CE}$ and $\eta_{\mathrm{E}}$. However, the current demand and the methane production rate, were triplicated, likely because the higher substrate availability caused by the continuous $\mathrm{CO}_{2}$ supply in the form of a saturated solution.

\section{Microbial activity of the biocathode}

The presence of only one genus of archaea responds to the specific conditions applied to the biocathode. Methanobacterium genus was described as an hydrogenotrophic methanogen by Kotelnikova and co-workers. ${ }^{41}$ This genus was responsible for methane production in the studied biocathode. Previous studies already reported the dominance of Methanobacterium sp. in methane-producing biocathodes, with high similarities to Methanobacterium palustre.$^{\mathbf{6 , 9 , 1 1 , 4 2}}$ Both, direct and hydrogen mediated production, were observed in biocathodes dominated by Methanobacterium sp.

In contrast, the bacterial community was highly-diversified. The most abundant species which could play a role in the biocathode were examined. Methylocystis sp. is especially common near environments where methane is produced. The presence of methane in the biocathode favoured this microorganism. It has been described in previous articles that Methylocystis sp. is able to transform methane to $\mathrm{CO}_{2}$ under aerobic conditions. ${ }^{43}$ Its activity could advantage the archaea activity, removing the oxygen diffused from the anode to the biocathode, and creating an anaerobic environment. ${ }^{20}$ However, this reaction decreased the efficiency of the process due to the methane consumption, as suggested by other authors. ${ }^{42}$

Firmicutes members, such as Clostridium sp. have several environmental roles. Hydrogen production from organic compounds was demonstrated by six mesophilic Clostridia. ${ }^{\mathbf{4 4}}$ Recently, Firmicutes were identified in an autotrophic hydrogen producing biocathode. ${ }^{45}$

Anaerophaga sp. was identified in consortium of sulphatereducing bacteria in biofilms used to analyse the corrosion behavior. ${ }^{46}$ It was detected also in electricity producing bioanodes and its activity decreased in the long term because of the lack of dissolved electron acceptors, ${ }^{47}$ such as sulphate.

\section{Bioelectrochemical methane production}

According to the results obtained in the present study, the main reactions that took place inside the biocathode were represented in Fig. 4. Given the operational conditions, the relatively high methane production rates, and the biocathode microbial community composition, hydrogen was most likely used as intermediate for methane production. Liquid phase analyses did not reveal the presence of acetate, even at very low concentrations $\left(<5 \mathrm{mg} \mathrm{L}^{-1}\right)$, and formate production is unlikely at the poised cathode potential. ${ }^{14}$ Although hydrogen was not detected in the gas phase, previous studies demonstrated that it was produced not only electrochemically, but also by microorganisms of the biocathode community, such as Clostridium sp., that were able to catalyse its production. ${ }^{45}$ The CVs presented in this study supported the evolution of the hydrogen reductive wave towards lower current densities. Hydrogen catalytic wave increased in the CVs in presence of microorganisms, and remained after the medium exchange. Thus, it was suggested the ability of some microorganisms present in the biocathode, such as Clostridium sp., to attach to the electrode surface and catalyse hydrogen production at low cathode potentials. Hydrogenotrophic methanogens, such as Methanobacterium sp., have been reported to grow very rapidly in microbial electrolysis cells. ${ }^{48}$ Interspecies hydrogen transfer occurred between Clostridium sp. and Methanobacterium sp., which combined the hydrogen produced with $\mathrm{CO}_{2}$ to obtain methane, according to 
eqn (1). Although this was likely the predominant methane production mechanism, the combination of $\mathrm{CO}_{2}$ with protons and electrons according to eqn (2), could not be discarded as it likely occurred to a minor extent. In this sense, it was not clear whether the cathodic catalytic wave observed at $-190 \mathrm{mV}$ could be related to methanogens or sulphate-reducing bacteria, because both reactions occurred at similar theoretical potentials. ${ }^{\mathbf{1 3 , 4 9}}$ According to Su et al., 2012 the presence of the cathodic catalytic wave at the potential of $-190 \mathrm{mV}$ could be related to sulphate reduction..$^{50}$ Otherwise, Fu et al., 2015 demonstrated similar behaviour of a biocathode methanogenic community. ${ }^{15}$ In that study, the cathodic catalytic wave remained after the medium exchange, contrarily, in the present study the cathodic catalytic wave disappeared, which suggested that the methanogens of the present study were not attached to the electrode surface and likely used a mediator to deal with reducing power.

The relatively low CE observed during the operation of the BES was caused by the presence of cross-over reactions (Fig. 4). Some of these cross-over reactions were suggested and supported by the microbial community identification. The relatively high abundance of Methylocystis sp. suggested the presence of oxygen in the cathode. Since water oxidation occurred in the anode chamber, the oxygen generated in this reaction can diffuse to the cathode through the membrane. ${ }^{\mathbf{1 0}}$ In the cathode it was partly electrochemically reduced to water, due to the reducing conditions, and partly used by Methylocystis sp. to consume methane, which decreased the CE (see ESI, Table S1 $\dagger$ ). The presence of sulphate in the influent promoted the growth of sulphate reducing bacteria. This was suggested by the presence of Anaerophaga sp. which reduced $\mathrm{SO}_{4}{ }^{2-}$ in the liquid phase to $\mathrm{H}_{2} \mathrm{~S}$. Since sulphate reducers and methanogens are direct competitors for hydrogen, the activity of the methanogens, and therefore the $\mathrm{CE}$, decreased due to the presence of this microorganisms in the biocathode (Table S1†). ${ }^{51}$ Although oxygen was the main electron sink, sulphate reduction was

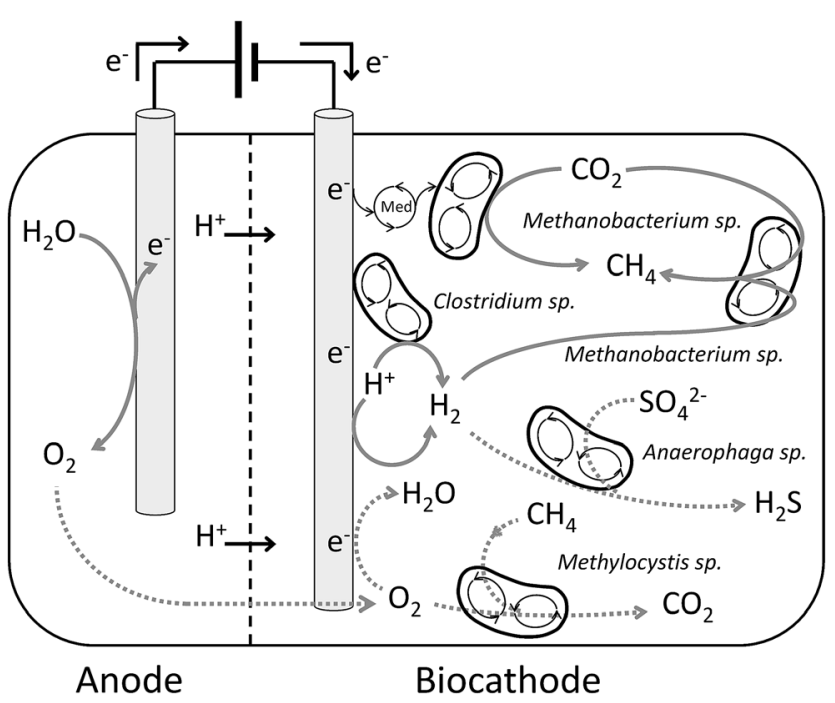

Fig. 4 Schematic representation of the methane producing (solid lines), and cross-over (dashed lines) reactions that took place in the biocathode. another cross-over reaction that decreased the $\mathrm{CE}$ of the process. However, the effect of sulphate reduction on the $\mathrm{CE}$ compared to oxygen was 100 and 10 times lower during batch and continuous operation, respectively (Table S1 $\dagger$ ). Another potential electron sink is the production of hydrogen as intermediate. At such low cathode potential, hydrogen was used as mediator to produce methane through hydrogenotrophic methanogenesis.. ${ }^{\mathbf{1 0} 11}$ Gas quantification, especially when hydrogen is present, is not accurate as it may diffuse out of the reactor through the connectors, the tubes, or the membrane, therefore part of the CE losses could have been caused by these reasons. $^{52-54}$

\section{Perspectives}

The present study demonstrated that the main methane production mechanism of the studied BES was hydrogen mediated. Hydrogenotrophic methanogens, such as Methanobacterium sp. drove methane production. It was suggested that syntrophic interactions between bacteria and archaea species present in the microbial community sustained the development of the biocathode and allowed for the production of methane. However, some of these interactions decreased the efficiency of the process. Understanding of the microbial community involved in methane production in BES and its interaction with the cathode electrode could lead to the development of practical applications for BES as a biogas upgrading process.

Nowadays, the methane content of the biogas can be increased through water scrubbing, releasing $\mathrm{CO}_{2}$ to the atmosphere in a stripping unit according to Fig. 5A. However, this study has shown the potential of BES in the field of biogas upgrading. The replacement of the stripping unit by a BES according to Fig. 5B could increase the yield of the process in terms of carbon utilisation, and therefore reduce the $\mathrm{CO}_{2}$ emissions, especially when renewable energy is used to drive the process. Typically, the effluent from an absorption tower for biogas upgrading has a $\mathrm{CO}_{2}$ and methane content in the solution of around $96 \%$ and $4 \%$, respectively, when this effluent was treated with the BES, an additional amount of biogas was produced, which was composed by $65-85 \% \mathrm{CH}_{4}, 15-35 \% \mathrm{CO}_{2}$ and $1-8 \% \mathrm{O}_{2}$. The present study demonstrated the robustness of the operation at long term (i.e. more than 420 days) of a BES using $\mathrm{CO}_{2}$ absorbed from biogas and producing methane. The methane production rate obtained during continuous operation was $15.35 \mathrm{mmol} \mathrm{m}^{-2}$ per day with a CE of $68.9 \pm 0.8 \%$, which was three times higher compared to the best results obtained during batch tests. A recent study by Siegert and coworkers suggested that the production rate could be even more increased by choosing a good combination of anode and cathode materials. ${ }^{16}$

The energy efficiency of the process was found in this study as the key bottleneck for scalability and applicability of BES for biogas upgrading. The kWh recovered in the form of methane represented $39.7 \pm 1.3 \%$ of the $\mathrm{kW} h$ supplied to the BES. Accordingly, the actual energy efficiency could restrict the potential application of this technology to the energy storage 

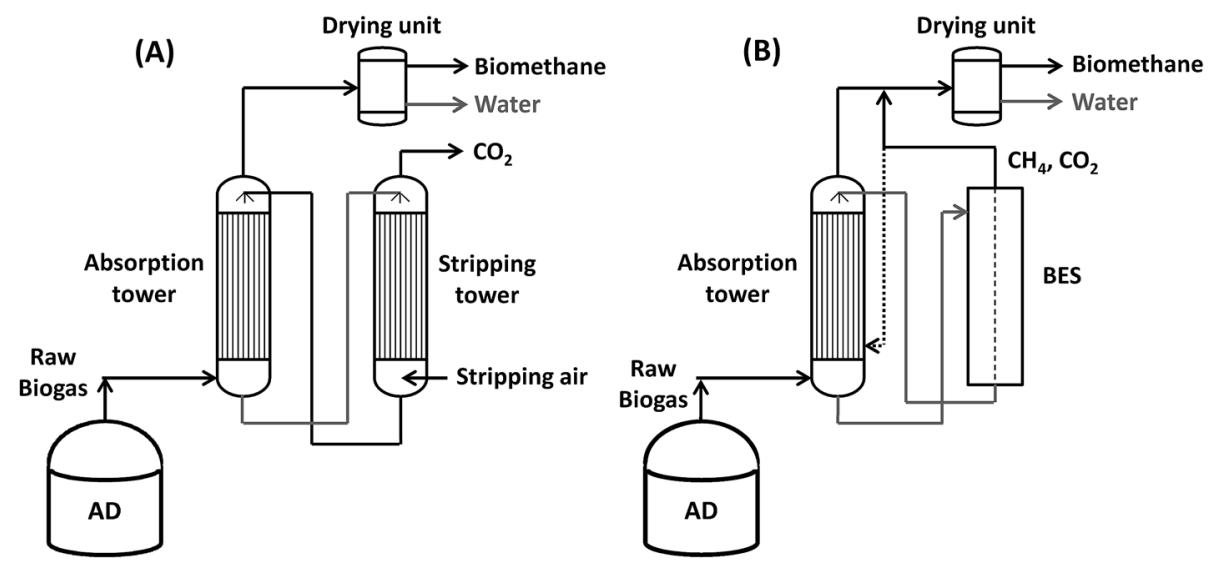

Fig. 5 Schematic representation of a typical water scrubbing-like biogas upgrading process (A), and the proposed modification of the process by the use of a BES instead of a stripping tower (B).

during off-peak energy production periods, ${ }^{55}$ or renewable energy harvesting and storage in the form of methane, which is easier handled than electricity and can be distributed through the existing gas grid. ${ }^{2}$ Regarding the energy efficiency, the oxidative conditions of the anode could be used to carry out profitable reactions to increasing the overall energy efficiency and the value of the process. In a study carried out by Luo and colleagues, the authors demonstrated the production of methane obtaining the electrons from a salinity gradient in the anode by reverse electrodialysis. ${ }^{56}$ This process avoided part of the energy consumption and the presence of oxygen, which allowed for the production of nearly pure methane in the biocathode, with relatively high CE. Thus, avoiding oxygen in the anode could be a useful strategy to increase the efficiency in future applications.

Finally, an exhaustive cost-benefit analysis needs to be performed to discern whether the application of the technology proposed in the present study would be economically feasible to replace a stripping tower.

\section{Conclusions}

This study demonstrated the production of methane using the simulated effluent of a biogas scrubbing-like unit as the sole carbon source in a BES. Methane obtained from the biocathode increased linearly with time and was directly dependent on the current demand of the BES. The viability and robustness of the system at long term was demonstrated, obtaining the maximum production rate of $15.35 \mathrm{mmol} \mathrm{m}^{-2}$ per day operating the BES in continuous flow. The microbial community from the biocathode was identified, being the archaea Methanobacterium the dominant genus. The reactions that took place in the biocathode were elucidated. The methane production mechanism was found to be mainly hydrogenotrophic methanogenesis using hydrogen that was bioelectrochemically produced in the biocathode. Cross-over reactions, such as oxygen and sulphate reduction, and methane oxidation were found to decrease the $\mathrm{CE}$ of the process.
The results presented in this study highlight the application of BES in the field of biogas upgrading technologies, to increase the overall yield of the process and to reduce $\mathrm{CO}_{2}$ emissions. These results open the door to further applications such as energy storage or production of biomethane to inject into the gas grid or use as a vehicle fuel.

\section{Acknowledgements}

This research was financially supported by the Spanish Government (CTQ 2014-53718-R). P. B-V. and A. V-P. were supported by a project grant from the Catalan Government (2014 FIB1 00119 and 2014 FI-B 00093). LEQUIA has been recognised as consolidated research group by the Catalan Government with code 2014-SGR-1168. Authors acknowledge the collaboration of Lluis Bañeras from the Group of Molecular Microbial Ecology (University of Girona), who helped with the microbial analyses.

\section{References}

1 C. Da Costa Gomez, The Biogas Handbook, Woodhead Publishing, 2013.

2 M. Persson, O. Jönsson and A. Wellinger, IEA Bioenergy, Task 37, 2006.

3 E. Ryckebosch, M. Drouillon and H. Vervaeren, Biomass Bioenergy, 2011, 35, 1633-1645.

4 International Energy Agency (IEA), http:/www.ieabiogas.net/plant-list.html?file=files/daten-redaktion/ download/Up-grading_Plant_List.xls, 2014.

5 L. Appels, J. Baeyens, J. Degrève and R. Dewil, Prog. Energy Combust. Sci., 2008, 34, 755-781.

6 C. Koch, A. Kuchenbuch, J. Kretzschmar, H. Wedwitschka, J. Liebetrau, S. Müller and F. Harnisch, RSC Adv., 2015, 5, 31329-31340.

7 T. Bo, X. Zhu, L. Zhang, Y. Tao, X. He, D. Li and Z. Yan, Electrochem. Commun., 2014, 45, 67-70.

8 K. Sasaki, M. Morita, D. Sasaki, S. Hirano, N. Matsumoto, A. Watanabe, N. Ohmura and Y. Igarashi, Bioresour. Technol., 2011, 102, 6837-6842. 
9 S. Cheng, D. Xing, D. F. Call and B. E. Logan, Environ. Sci. Technol., 2009, 43, 3953-3958.

10 M. C. A. A. Van Eerten-jansen, A. T. Heijne, C. J. N. Buisman and H. V. M. Hamelers, Int. J. Energy Res., 2012, 36, 809-819.

11 M. Villano, F. Aulenta, C. Ciucci, T. Ferri, A. Giuliano and M. Majone, Bioresour. Technol., 2010, 101, 3085-3090.

12 P. Batlle-Vilanova, S. Puig, R. Gonzalez-olmos, A. Vilajeliupons and L. Bañeras, Int. J. Hydrogen Energy, 2014, 39, 1297-1305.

13 K. Rabaey and R. A. Rozendal, Nat. Rev. Microbiol., 2010, 8, 706-716.

14 M. C. A. A. Van Eerten-Jansen, N. C. Jansen, C. M. Plugge, V. de Wilde, C. J. N. Buisman and A. T. Heijne, J. Chem. Technol. Biotechnol., 2015, 90, 963-970.

15 Q. Fu, Y. Kuramochi, N. Fukushima, H. Maeda, K. Sato and H. Kobayashi, Environ. Sci. Technol., 2015, 49, 1225-1232.

16 M. Siegert, M. D. Yates, D. F. Call, X. Zhu, A. Spormann and B. E. Logan, ACS Sustainable Chem. Eng., 2014, 2, 910-917.

17 A. J. M. Stams and C. M. Plugge, Nat. Rev. Microbiol., 2009, 7, 568-577.

18 D. R. Lovley, Energy Environ. Sci., 2011, 4, 4896.

19 A.-E. Rotaru, P. M. Shrestha, F. Liu, B. Markovaite, S. Chen, K. Nevin and D. Lovley, Appl. Environ. Microbiol., 2014, 80, 4599-4605.

20 P. Batlle-Vilanova, S. Puig, R. Gonzalez-Olmos, M. D. Balaguer and J. Colprim, J. Chem. Technol. Biotechnol., 2015, DOI: 10.1002/jctb.4657.

21 R. S. Tanner, L. M. Miller and D. Yang, Int. J. Syst. Bacteriol., 1993, 43, 232-236.

22 APHA, Standard methods for the examination of water and wastewater, American Public Health Association, Washington DC, 19th edn, 2005.

23 B. E. Logan, H. V. M. Hamelers, R. A. Rozendal, U. Schröder, J. Keller, S. Freguia, P. Aelterman, W. Verstraete and K. Rabaey, Environ. Sci. Technol., 2006, 40, 5181-5192.

24 S. A. Patil, S. Gildemyn, D. Pant, K. Zengler, B. E. Logan and K. Rabaey, Biotechnol. Adv, 2015, DOI: 10.1016/ j.biotechadv.2015.03.002.

25 G. K. Rader and B. E. Logan, Int. J. Hydrogen Energy, 2010, 35, 8848-8854.

26 N. Pous, C. Koch, J. Colprim, S. Puig and F. Harnisch, Electrochem. Commun., 2014, 49, 93-97.

27 G. Muyzer, E. C. De Waal and a. G. Uitterlinden, Appl. Environ. Microbiol., 1993, 59, 695-700.

28 E. F. DeLong, Proc. Natl. Acad. Sci. U. S. A., 1992, 89, 5685-5689.

29 P. D. Schloss, S. L. Westcott, T. Ryabin, J. R. Hall, M. Hartmann, E. B. Hollister, R. A. Lesniewski, B. B. Oakley, D. H. Parks, C. J. Robinson, J. W. Sahl, B. Stres, G. G. Thallinger, D. J. Van Horn and C. F. Weber, Appl. Environ. Microbiol., 2009, 75, 7537-7541.

30 R. C. Edgar, B. J. Haas, J. C. Clemente, C. Quince and R. Knight, Bioinformatics, 2011, 27, 2194-2200.

31 R. C. Edgar, Nat. Methods, 2013, 10, 996-998.

32 J. R. Cole, Q. Wang, E. Cardenas, J. Fish, B. Chai, R. J. Farris, A. S. Kulam-Syed-Mohideen, D. M. McGarrell, T. Marsh, G. M. Garrity and J. M. Tiedje, Nucleic Acids Res., 2009, 37, D141-D145.
33 T. A. Hall, Nucleic Acids Symp. Ser., 1999, 41, 95-98.

34 B. D. Ondov, N. H. Bergman and A. M. Phillippy, $B M C$ Bioinformatics, 2011, 12, 385.

35 J. C. López-Gutiérrez, S. Henry, S. Hallet, F. Martin-Laurent, G. Catroux and L. Philippot, J. Microbiol. Methods, 2004, 57, 399-407.

36 D. Kemnitz, S. Kolb and R. Conrad, FEMS Microbiol. Ecol., 2007, 60, 442-448.

37 C. W. Marshall, D. E. Ross, E. B. Fichot, R. S. Norman and H. D. May, Appl. Environ. Microbiol., 2012, 78, 8412-8420.

38 M. Siegert, X.-F. Li, M. D. Yates and B. E. Logan, Front. Microbiol., 2014, 5, 778.

39 B. J. Mathis, C. W. Marshall, C. E. Milliken, R. S. Makkar, S. E. Creager and H. D. May, Appl. Microbiol. Biotechnol., 2008, 78, 147-155.

40 G. Luo, D. Karakashev, L. Xie, Q. Zhou and I. Angelidaki, Biotechnol. Bioeng., 2011, 108, 1816-1827.

41 S. Kotelnikova, A. J. L. Macario and K. Pedersen, Int. J. Syst. Bacteriol., 1998, 48, 357-367.

42 M. C. A. A. Van Eerten-jansen, A. B. Veldhoen, C. M. Plugge, A. J. M. Stams, C. J. N. Buisman and A. T. Heijne, Archaea, 2013, 2013, 481784.

43 L. Y. Stein, F. Bringel, A. a DiSpirito, S. Han, M. S. M. Jetten, M. G. Kalyuzhnaya, K. D. Kits, M. G. Klotz, H. J. M. O. den Camp, J. D. Semrau, S. Vuilleumier, D. C. Bruce, J.-F. Cheng, K. W. Davenport, L. Goodwin, S. Han, L. Hauser, A. Lajus, M. L. Land, A. Lapidus, S. Lucas, C. Médigue, S. Pitluck and T. Woyke, J. Bacteriol., 2011, 193, 2668-2669.

44 Z. Ren, T. E. Ward, B. E. Logan and J. M. Regan, J. Appl. Microbiol., 2007, 103, 2258-2266.

45 L. Jourdin, S. Freguia, B. C. Donose and J. Keller, Bioelectrochemistry, 2015, 102, 56-63.

46 F. M. AlAbbas, C. Williamson, S. M. Bhola, J. R. Spear, D. L. Olson, B. Mishra and A. E. Kakpovbia, J. Mater. Eng. Perform., 2013, 22, 3517-3529.

47 B. Cercado, N. Byrne, M. Bertrand, D. Pocaznoi, M. Rimboud, W. Achouak and A. Bergel, Bioresour. Technol., 2013, 134, 276-284.

48 R. C. Tice and Y. Kim, Int. J. Hydrogen Energy, 2014, 39, 30793086.

49 P. K. Dutta, J. Keller, Z. Yuan, R. A. Rozendal and K. Rabaey, Environ. Sci. Technol., 2009, 43, 3839-3845.

50 W. Su, L. Zhang, Y. Tao, G. Zhan, D. Li and D. Li, Electrochem. Commun., 2012, 22, 37-40.

51 D. R. Lovley, D. F. Dwyer and M. J. Klug, Appl. Environ. Microbiol., 1982, 43, 1373-1379.

52 J. Ditzig, H. Liu and B. E. Logan, Int. J. Hydrogen Energy, 2007, 32, 2296-2304.

53 R. A. Rozendal, H. Hamelers, G. Euverink, S. Metz and C. J. N. Buisman, Int. J. Hydrogen Energy, 2006, 31, 1632-1640.

54 R. A. Rozendal, A. W. Jeremiasse, H. V. M. Hamelers and C. J. N. Buisman, Environ. Sci. Technol., 2008, 42, 629-634.

55 G. A. Olah, G. K. S. Prakash and A. Goeppert, J. Am. Chem. Soc., 2011, 133, 12881-12898.

56 X. Luo, F. Zhang, J. Liu, X. Zhang, X. Huang and B. E. Logan, Environ. Sci. Technol., 2014, 48, 8911-8918. 